\title{
Evaluation of Influence of Innovation on Enterprise Productivity
}

Zhadyra Sailaubekovna Mukhametzhanova, ${ }^{+*}$ Assima Narbekovna Daurenbekova, ${ }^{\dagger}$ Gaukhar Kaldanovna Zhanibekova, ${ }^{i}$ Kulyash Shaimoldenovna Syzdykova, ${ }^{*}$ and Gulnar Kaliakparova ${ }^{*}$

\section{Abstract}

In small and medium-sized enterprises of Kazakhstan, not enough attention has been paid to the relationship between innovation and enterprise productivity, as well as the measurement of the existing relationship. Therefore, the purpose of the article is to study the impact of innovations (productive or process, organisational, marketing) on the productivity of small and medium-sized enterprises of Kazakhstan. The data used in the research were obtained from the review conducted by the Business Environment and Enterprise Performance Survey and the European Bank for Reconstruction and Development and the World Bank. Besides, the results of the survey among small and medium-sized enterprises of Kazakhstan conducted in 2012-2014 were considered as well. Based on the survey results, descriptive statistics and correlation and regression analysis were conducted. According to the results of the study and econometric analysis, model creation and evaluation, the positive impact of innovation, investment and R\&D on the performance of small and medium-sized enterprises in Kazakhstan was established. In conclusion, it can be stated that in order to increase the level of innovative activity, enterprises must focus their activities on expanding the production of new or improved products, be competitive in the market due to the application of new technologies and improve the quality of products.

Keywords: Innovation, Productivity, Innovative Activity, R\&D, Investment, Small and Medium-Sized Enterprises

\footnotetext{
${ }^{\dagger}$ Narxoz University, Zhandosov Street, 55, Almaty, 050035, Kazakhstan

${ }^{*}$ Corresponding Author, Email: jadira-76@mail.ru

îCaspian University, Seifullin Avenue, 521, Almaty, 050000, Kazakhstan

${ }^{¥}$ Kainar Academy, Satpaev Street, 7A, Almaty, 050013, Kazakhstan

(C) 2019 Mukhametzhanova et al. This is an Open Access article distributed under the terms of the Creative Commons Attribution License (http://creativecommons.org/licenses/by/2.0), which permits unrestricted use, distribution, and reproduction in any medium, provided the original work is properly cited.
} 


\section{Introduction}

At enterprises and organisations that are considered to be the main links in the country's economy, a thriving organisation of innovative activity provides an excellent opportunity for achieving the intended goal. Innovative ideas and their continuous implementation are the main factors in the development of any enterprise. For economic development and increase in the social level of population, it is necessary to change the types of products and services, constantly update them, and, on the basis of innovations and innovative technologies, improve production and management functions. The application of innovation and innovative ideas, as well as scientific and technological achievements and technologies in production, is of particular importance in the development of a country's economy and in raising the standard of living of the population. This, in turn, affects the increase in labour and enterprise productivity and the emergence of new industries, as well as the increase in the competitiveness of domestic goods in the world market and quality of services provided (Mukhametzhanova, 2017b; insert few more references). Figure 1 demonstrates the innovative activities of the different organisations in Kazakhstan.

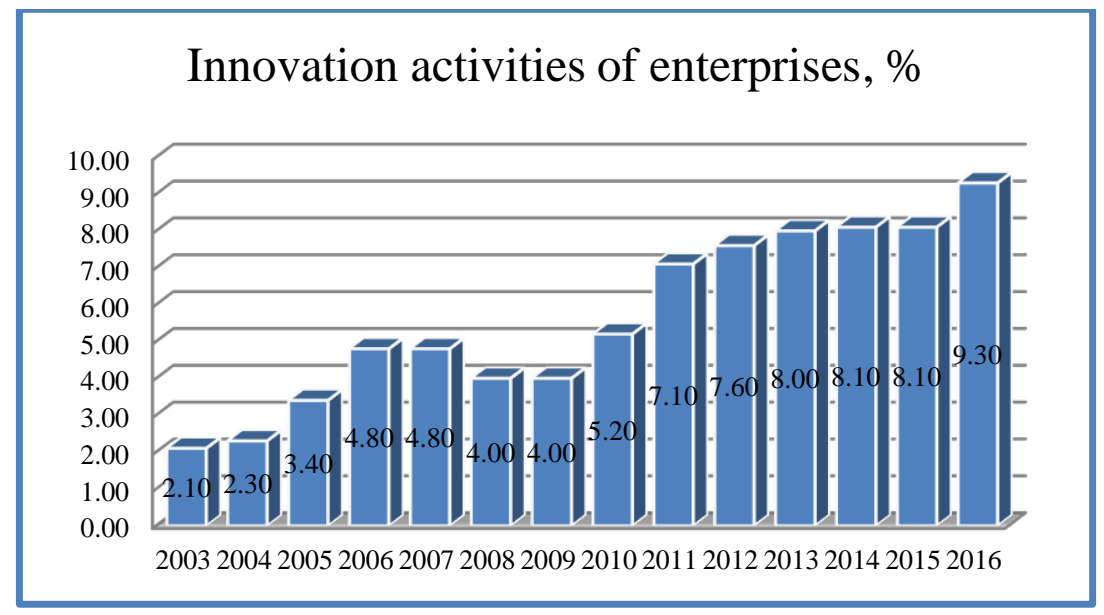

Figure 1: Innovative Activities of Enterprises in Kazakhstan, 2003-2016. Source: http://www.stat.gov.kz

In implementing innovative programs in Kazakhstan, the level of innovative activity of domestic enterprises exerts a particular influence. As can be seen from Figure 1, the level of innovative activity of enterprises in Kazakhstan has increased significantly (Mukhametzhanova, 2017a).

At present, if one looks at the level of activity of enterprises in the innovation sector, in economically developed countries, such as the USA, European countries, Japan and South Korea, it is equal to $50 \%$. In the Commonwealth of Independent States (CIS) countries, it is much lower; in Russia, this figure is $12 \%$ and in Kazakhstan - about $10 \%$. The level of innovative activity of enterprises in Kazakhstan increased
4.4 times: if in 2003, it was $2.1 \%$, then in 2010 $5.2 \%$ and in $2016-9.3 \%$ (Agency for Statistics of the Ministry of National Economy of the Republic of Kazakhstan, n.d.).

Even though the concept of the innovative economy already exists in Kazakhstan, its structure has not been explicitly studied yet.

In light of this background, the paper begins with a brief review of relevant, literature. This is followed by a discussion of the materials and methods entailed. The results and discussion section critically discusses the findings.

\section{Literature Review}

The study of influence and interrelation of innovation and enterprise productivity over the 
past few years has been one of the most important problems covered in foreign scientists' research. Despite the fact that many empirical studies have been carried out in connection with this problem, scholars have not paid enough attention to measuring the impact of innovation on productivity in small and medium-sized enterprises (Hadhri, Arvanitis \& M'Henni, 2016; Hall, Lotti \& Mairesse, 2009; Vlachy, 2017). Based on the data concerning small and medium-sized enterprises in Italy, for the first time, a study on the problems of the interrelation between innovation and enterprise productivity was conducted which measured their interrelationship (Mairesse et al., 2005). In Kazakhstan, too, the problems of the interconnection of innovation and enterprise productivity in small and medium-sized enterprises, as well as the measurement of their interrelationships, are not given special attention.

Definition and study of the influence of innovation (productive or process, organisational, marketing) on the productivity of small and medium-sized enterprises in Kazakhstan is the goal of this research. Theoretical and methodological foundations of the research are works of Kazakh and foreign economists, reviewing the issue under study.

Based on the results of the study and econometric analysis, model creation and evaluation, the positive impact of innovation, investment and R\&D on the performance of small and medium-sized enterprises in Kazakhstan was established.

Between small and medium-sized enterprises, $R \& D$, technology and innovation (productive and process), there is a mutual influence (Hoffman et al., 1998). This was already proposed in the late ' 90 s and is still being investigated.

For enterprises in the processing industry (for example, food or textile), the result of an innovative product is particularly important (Mairesse et al., 2005). Therefore, an increase in productivity is suggested after the release of new products. A comprehensive assessment model was developed and presented by Shyman (Sustainable Hydrothermal Manufacturing of
Nanomaterials), who studied and introduced new technologies in the production and application of nanomaterials. The experience gained in this research is easily applicable to other cases of cost analysis related to innovation (Vlachy, 2017).

It has also been determined that innovation has a significant impact on enterprise productivity (Hall, 2011). The results of a company's research and the intensity of R\&D show that investment in equipment increases the productivity and innovation implementation process. These innovations have a positive effect on the performance of the company as a whole (Hall et al., 2009).

One of the essential criteria for supporting innovation is the involvement of the largest companies in various sectors of the economy through the creation of scientific centres and institutions that can assist in developing companies (Hadhri et al., 2016). In the next section, we discuss the materials and methods applied in this research.

\section{Materials and Methods}

The data we used for the analysis was obtained from the official website of the Agency for Statistics of the Republic of Kazakhstan, Business Environment and Enterprise Performance Survey and the European Bank for Reconstruction and Development and the World Bank (2018), as well as the results of the survey among small and medium-sized enterprises of Kazakhstan from 2012 to 2014. The data covers 536 small and medium-sized enterprises. BEEPS $V$, the Bank for Reconstruction and Development and the World Bank conducted a survey in 30 countries with economies in the state of transition, including Kazakhstan, where the data set covers 15,883 enterprises (micro, small and medium-sized, as well as large firms).

Based on the results of the survey, descriptive statistics and correlation-regression analyses were carried out. The data of the annual report of enterprises showed the productivity that was obtained for the creation of the econometric model. 
The article uses modern analytical methods of research, including econometric methods, the methods of generalisation and comparison of the obtained results.

Many works devoted to the measurement of innovation are based on questionnaires. In innovative questionnaires, the measurement of innovation is usually carried out in two ways. The first way is based on the kind of innovation the enterprise has introduced over the last three years (productive or process, organisational, marketing). The second way is based on the share of an innovative product in the market calculated through the definition of the volume of sales of products. Many authors believe that

measuring using the second way is the better solution, as it shows the importance of innovation for the enterprise (Acs, \& Audretsch, 1988; Hall, 2011) explicitly. The quantitative analysis of the influence of an innovative trend in the firm on reducing costs has been carried out (Griffith et al., 2006). The main work in this direction passes through several periods. In the first period, the production function of CobbDouglas is applied to the basic model. The productivity of enterprises is measured through the production function of Cobb-Douglas production function, that is, the dependence of the volume of production (Q) on the components of its production factors, the labour force (L) and capital (C):

$$
Q=A L^{\alpha} C^{\beta}
$$

where $A$ is an indicator of overall productivity. If $\alpha+\beta=1$, then the recurrence is constant; if $\alpha+\beta>1$, then the recurrence is extended; if $\alpha+\beta<1$, then the recurrence is regressive (Hall, 2011).

The model of the second period considers the relationship between the production function and innovation:

$$
\left\{\begin{array}{l}
\mathrm{PROD}_{i}=R D i \alpha+x_{i} \beta+\varepsilon_{1 i} \\
\text { PROC }_{i}=R D_{i} \alpha+x_{i} \beta+\varepsilon_{2 i}(2)
\end{array}\right.
$$

where RDi is the intensity of R\&D in innovation, PRODi and PROCi - innovation (productive and process), $\varepsilon$ - model error.

The importance of models consists of obtaining conclusions and assessments based on econometric models related to innovation trends and profitability.

\section{Results}

In developed countries, innovation plays a special role in increasing the productivity of an enterprise. In Kazakhstan, to increase the productivity of an enterprise, it is necessary to determine the role of the innovation strategy and then consider ways of introducing it into the enterprise.

The development of innovation in the enterprise leads to an increase in the productivity of enterprise since in order to find its place in the market, the enterprise must be very different from other enterprises. The development of scientific and technological progress at the enterprise at a high level directly affects the increase in the volume of production and the work of the enterprise in the right direction.

For small and medium-sized enterprises in Kazakhstan, we performed correlationregression analysis to determine the probability of innovative impact on the enterprise's productivity (Table 1 ). The simulation was carried out using the GRETL program (Kufel, 2007).

The results of the simulation are illustrated in Table 1. 


\begin{tabular}{|c|c|c|c|}
\hline NO. & Type of model & $\mathbf{R}^{\wedge} \mathbf{2}$ & Se \\
\hline $\begin{array}{l}\text { Model Product } \\
\text { Innovation }\end{array}$ & $\mathrm{Ym}_{1}=32.717-1.946 \times 13-18.418 \times 14+11.881 \times 17+\varepsilon$ & 0.87 & 8.79 \\
\hline $\begin{array}{l}\text { Model Process } \\
\text { Innovation }\end{array}$ & $\mathrm{Ym}_{2}=1.406+0.060 \times 29+\varepsilon$ & 0.21 & 0.33 \\
\hline $\begin{array}{l}\text { Model } \\
\text { Organisational } \\
\text { Innovation }\end{array}$ & $\mathrm{Ym}_{3}=-0.410+0.595 \times 17+\varepsilon$ & 0.04 & 2.02 \\
\hline $\begin{array}{l}\text { Model } \\
\text { Marketing } \\
\text { Innovation }\end{array}$ & $\mathrm{Ym}_{4}=0.744+0.247 \mathrm{X} 16+\varepsilon$ & 0.01 & 1.27 \\
\hline $\begin{array}{l}\text { Model } \\
\text { Productivity } \\
\text { Enterprises }\end{array}$ & $\mathrm{Ym}_{5}=34.55+0.0003 \times 1+0.0001 \times 2-7.369 \times 3+\varepsilon$ & 0.07 & 18.20 \\
\hline
\end{tabular}

In general, as it can be seen from Table 1, the expenditure on R\&D, including staff costs, materials and the purchase of fixed assets, over the past three years, this institution has spent on R\&D with other companies and the size of the firm (micro $<5$, small $>=5$ and $<=19$, medium $>=20$ and $<=99$, large $>=100$ ) has a positive impact on innovation (new or significantly improved products, annual sales percentage), $\mathrm{R}=0.87$.

$\mathrm{Ym}_{1}=32.717-1.946 \times 13-18.418 \times 14+11.881 \times 17+$ $\varepsilon \quad(2)$

where $\varepsilon$ is the model error.

If one considers a probability of $95 \%$, then an increase in one unit of expenditure for the conduct of R\&D work and the size of the firm means an increase in innovation, on average, by one unit.

In the second model $\mathrm{R}^{2}=0.87$, it can be seen that innovation is $89 \%$ associated with internal $R \& D$ expenditures and firm size, and the rest is related to unrecorded factors. According to Fisher's criterion, $F(4,10)=28.54>P$-value $(F)=0.004$, this means that the factor randomness hypothesis is not accepted. The White test $L M=3.73 \quad p$-value $=P(C h i-$ square $(5)>3.73)=0.59$ indicates the absence of heteroscedasticity, and the Ramsey test (RESET $p$-value $=P(F(2,1)>1.94)=0.45$ shows that equation (2) is adequate. The errors are distributed according to the normal law Chisquare(2) $=0.13, p$-value $=0.94$ (Figure 2 ).

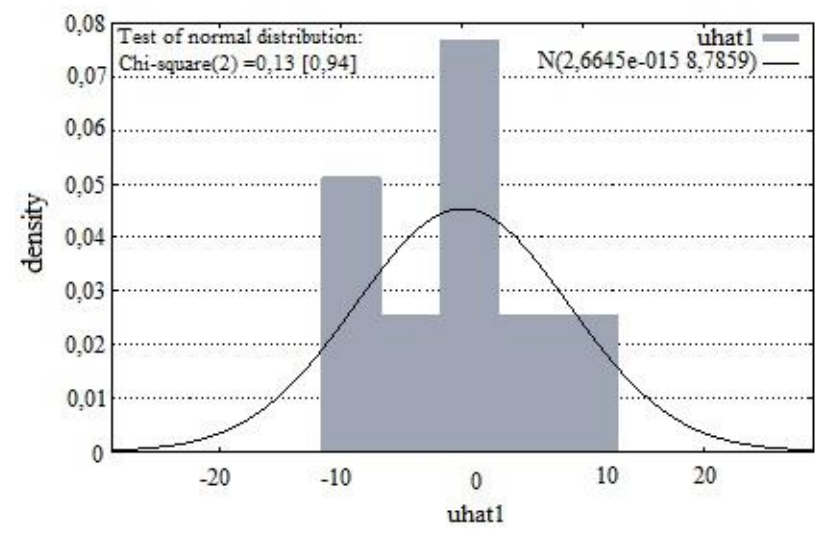

Figure 2: Normal Distribution of Innovation Errors (New or Significantly Improved Products). Source: BEEPS V and The European Bank for Reconstruction and Development and the World Bank 


\section{$\mathrm{Ym}_{2}=1.406+0.060 \times 29+\varepsilon$}

In the third model $R^{2}=0.21$, one can see that innovation (process) is $21 \%$ associated with inventions, patents or know-how, and the remaining $79 \%$ are related to other factors. According to Fisher's criterion, $F(4,58)=14.56>P$ value $(F)=2.73$, this means that the factor

$$
\mathrm{Ym}_{3}=-0,410+0,595 \times 17+\varepsilon
$$

In the fourth model $\mathrm{R}^{2}=0.04$, one can see that the innovation (organisational) is $4 \%$ associated with the size of the firm, and the remaining $96 \%$ are related to other factors. According to the Fisher criterion $F(2,75)=1.57>P$-value $(F)=0.22$, this means that the factor randomness hypothesis is

$$
\mathrm{Ym}_{4}=0,744+0,247 \times 16+\varepsilon
$$

In the fifth model $R^{2}=0.01$, one can see that innovation (marketing) is $1 \%$ related to the size of the firm, and the remaining $99 \%$ are related to other factors. According to the Fisher criterion, $F(2,72)=2.45>P$-value $(F)=0.09$, this means that the factor randomness hypothesis is not

$$
\mathrm{Ym}_{5}=34.55+0.0003 \times 1+0.0001 \times 2-7.369 \times 3+\varepsilon
$$

If one considers with $95 \%$ probability, the increase of one unit of the company's fixed capital and domestic R\&D expenditures, this gives the increase in the enterprise's productivity on average by one unit (Rakhmetova, 2015).

In (6) of the model $R^{2}=0.07$, one can see that the enterprise's productivity is $7 \%$ associated with the enterprise's fixed capital and investments, accepted. The White test $L M=0.91, p$ value $=P($ Chi-square $(5)>0.91)=0.97$ indicates the absence of heteroscedasticity, and the Ramsey test (RESET $p$-value $=P(F(2,60 \quad)>3.22)=0.05$ shows that equation (5) is adequate.

internal R\&D expenditures, and the rest - on the shares of unaccounted factors. According to the Fisher criterion, $F(4,15)=2.19>P$-value $(F)=0.12$, this means that the factor randomness hypothesis is not accepted. The White test $L M=9.93 \quad p$-value $=P($ Chi-square $(14)>9.93)=0.77$ indicates the absence of heteroscedasticity, and the Ramsey test (RESET $p$-value $=P(F(2$, 41) $>0.32$ ) $=0.73$ shows that equation (6) is adequate.

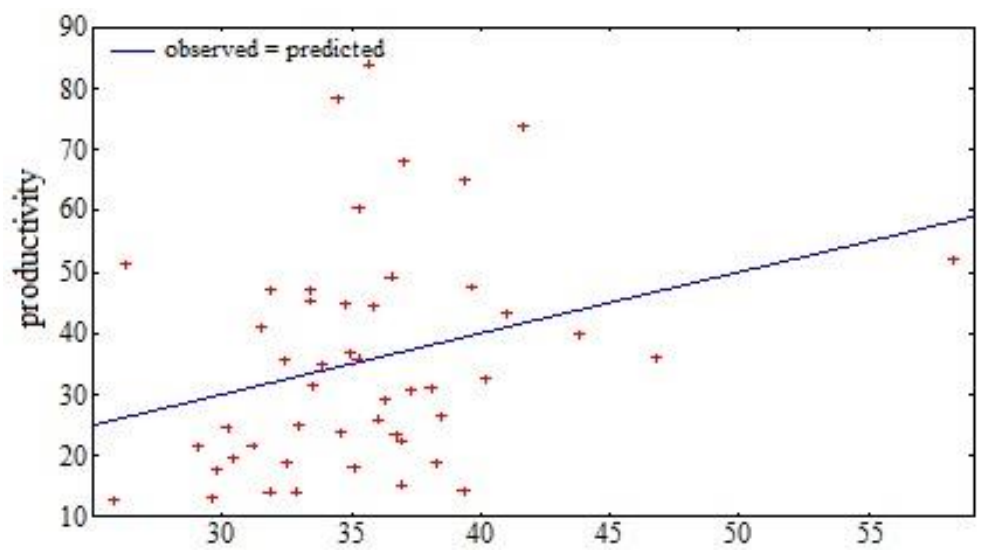

Figure 3:Observed and Predicted Enterprise Productivity Values.

Source: BEEPS V and The European Bank for Reconstruction and Development and the World Bank 
It can be seen from Figure 3 that based on the observed and predicted values calculated by the equations of predicted values of enterprise productivity, the predicted values of recent years have greatly increased (Kazakhstan Stock Exchange JSC, n.d.).

\section{Discussion}

Based on the results of the econometric analysis, we can say that among the considered models (Table 1), the most statistically significant is the second model.

According to the results of the research and econometric analysis, it is possible to notice that innovations have a positive influence on the productivity of small and medium-sized enterprises of Kazakhstan. Enterprises increase productivity by raising subsidies, attracting investments, conducting R\&D, applying new technologies and producing high-quality new or improved products.

It is especially noticeable that conducting $R \& D$ has a significant influence on the production of innovative new or improved products. Investments allow providing the production with new devices and technological innovations.

The obtained results of the study concerning small and medium-sized enterprises in Kazakhstan are comparable with the research conducted by K. Hoffman, M. Parejo, J. Bessant, and L. Perren (1998), B.H. Hall, F. Lotti, J. Mairesse (2009), R. Griffith, E. Huergo, J. Mairesse, and B. Peters (2006) and others.

\section{Conclusion}

In the article, based on the results of the models assessment, positive probabilities of the influence of innovations, $R \& D$ and investment on the productivity of small and medium-sized enterprises of Kazakhstan were determined, and their economic interpretation was conducted. Thus, in the implementation of innovative programs in Kazakhstan, the level of innovative activity of domestic enterprises has a particular influence of its own.

In conclusion, in order to increase the level of innovative activity of enterprises, it should be aimed at expanding the production of new or significantly improved products and increasing competitiveness in the market through the use of new technologies and the production of highquality products.

\section{References}

Acs, Z. J., \& Audretsch, D. B. (1988). Innovation in large and small firms: An empirical analysis. American Economic Review, 78(4), 678-690.

Agency for Statistics of the Ministry of National Economy of the Republic of Kazakhstan. (n.d.). Retrieved 12 March 2018 from

http://www.stat.gov.kz.

Business Environment and Enterprise Performance Survey (BEEPS V) and The European Bank for Reconstruction and Development and the World Bank. (2018).

Griffith, R., Huergo, E., Mairesse, J., \& Peters, B. (2006). Innovation and productivity across four European countries. Oxford Review of Economic Policy, 22(4), 483-498.

Hadhri, W., Arvanitis, R., \& M'Henni, H. (2016). Determinants of innovation activities in small and open economies: The Lebanese business sector. Journal of Innovation Economics \& Management, 3(21), 77-107.

Hall, B. H. (2011). Innovation and Productivity. Working Paper No. 17178. Retrieved 25 April 2018 from

http://www.nber.org/papers/w17178.

Hall, B. H., Lotti, F., \& Mairesse, J. (2009). Innovation and Productivity in SMEs: Empirical Evidence for Italy. Small Business Economics, 33, 13-33.

Hoffman, K., Parejo, M., Bessant, J., \& Perren, L. (1998). Small firms, R\&D, technology and innovation in the UK: A literature review. Technovation, 18(1), 39-55.

Kazakhstan Stock Exchange JSC. (n.d.).

Retrieved 25 April 2018, from

http://www.kase.kz/.

Kufel, T. (2007). Ekonometrika: Reshenie zadach $s$ primeneniem paketa programm GRETL [Econometrics: Solving problems using the GRETLS programme package]. Moscow: Goriachaia liniia-Telekom. 
Mairesse, J., Mohnen, P., \& Kremp, E. (2005). The the enterprises of Kazakhstan. In Modern Importance of R\&D and Innovation for Research of the Basic Directions of Technical and Productivity: A Re-Examination in Light of the Social Sciences: Materials of the International French Innovation Survey. Annales d'Economie Scientific and Practical Conference. Kazan, pp. et de Statistique, 79(80), 487-527. 703-706.

Mukhametzhanova, Zh. S. (2017a). Factor Rakhmetova, R. U. (2015). Econometrics: analysis of innovative activities in Kazakhstan. Textbook. Almaty: Ekonomika.

Statistika, 3(66), 114-122.

Vlachy, J. (2017). The Value of Innovation in

Mukhametzhanova, Zh. S. (2017b). The Nanotechnology. Engineering Economics, 28(5), economic analysis of the innovative activity of 535-541. 